\title{
MERCEDES DOTALES PARA MUJERES, O LOS PRIVILEGIOS DE SERVIR EN PALACIO (SIGLOS XVII-XVIII)'
}

\author{
F. Andújar Castillo \\ Universidad de Almería
}

\begin{abstract}
Resumen. En la España del Antiguo Régimen, la remuneración de los servicios en el seno de la Corte y, para los servidores de la Corte, constituyó un mundo peculiar que funcionó de acuerd o a convenciones particulares y con mecanismos de regulación propios, claramente diferenciados en el complejo flujo de intercambios que permanentemente se producían entre el monarca y sus servidores en torno a la economía de la gracia. Una de las formas de pago de servicios, reservada de forma casi exclusiva para servidores y servidoras de palacio, consistió en la concesión de mercedes dotales para casar convenientemente a mujeres, ora fuesen ellas mismas servidoras de la Casa de la Reino, ora fuesen hijas o sobrinas de quienes desempeñaban puestos en la Corte. Por la vía matrimonial los monarcas proveyeron magistraturas de justicia, empleos de consejero y, las más numerosas, plazas de contadores de la Contaduría Mayor de Cuentas.
\end{abstract}

Palabras clave: mujeres, provisión de empleos, dotes, patronazgo regio, cargos cortesanos, venalidad.

AbSTRACT. In Spain during the Old Regime, the remuneration for services within the Court, and for the servants of the Court, was a peculiar world that operated according to particular conventions and mechanisms of specific regulation, clearly differentiated in the complex flow of exchanges that occurred continuously between the monarch and his servers around the economy of grace. One form of payment for services, almost exclusively reserved for servers in the palace, was the granting of endowment grants to women to marry suitably. It

1 Trabajo recibido el 15/III/2010 y aceptado para su publicación el 15/IV/2010. El presente estudio se ha realizado en el marco del Proyecto de Investigación de I+D Venalidad de cargos y honores en la España del siglo XVIII (HAR2008-03180) financiado por el Ministerio de Ciencia e Innovación. 
didn't mind if they were servants of the house of the Queen, or whether they were daughters or nieces of those who held senior positions at court. So, through marriage, the monarchs provided tribunals of justice, counsellor employment and the most numerous, accountants in The Accounting Major Accounts.

Keywords: provision of charges, dowries, royal patronage, court offices, venality.

\section{La merced dotal. Concepto y tipologías}

Los estudios sobre la Corte y, dentro de ella, las Casas Reales, disfrutan en los últimos años de un renovado interés por parte de la historiografía modernista ${ }^{2}$. Son trabajos importantes para el conocimiento del funcionamiento del complejo entramado cortesano, de las plantas de las diferentes Casas, de su financiación y organización, pero resta mucho aún por conocer desde la perspectiva de la historia social del personal de Corte, de los innumerables servidores y servidoras que, en los más variados oficios trabajaban en palacio al servicio de los monarcas, algunos, y algunas, en puestos decisivos en los que disfrutaban de un excepcional capital relacional, sobre todo aquellos que se movían en las proximidades de las personas regias. Del mismo modo, resta bastante por saber acerca de las formas de acceso a los cargos palaciegos y los sistemas de transmisión de los mismos. Por el momento, tan sólo es posible avanzar que en la Corte, al menos en los siglos XVII y XVIII, período de estudio de esta aportación, el monarca proveyó los cargos de palacio y concedió mercedes siguiendo pautas propias y particulares que situaron al entorno cortesano como una singular isla en el conjunto de los servidores regios.

En la España del Antiguo Régimen, la remuneración de los servicios en el seno de la Corte y, para los servidores de la Corte, constituyó un mundo particular y peculiar que funcionó de acuerdo con convenciones particulares y con mecanismos de regulación propios, claramente diferenciados en el complejo flujo de intercambios que se producía entre el monarca y sus servidores en torno a la economía de la gracia ${ }^{3}$.

2 Nos exime de cualquier referencia adicional la actualizada bibliografía que se recoge en las dos últimas publicaciones del grupo de investigación del Instituto Universitario "La Corte en Europa" de la Universidad Autónoma de Madrid: MARTÍNEZ MILLÁN, J. - MARTÍNEZ LOURENÇO, Mª P. (Coords.): Las relaciones discretas entre las monarquias hispana y portuguesa: las casas de las reinas (siglos XV-XIX), Madrid, 2008, 3 vols.; MARTÍNEZ MILLÁN, J. - VISCEGLIA, Ma A.: La monarquía de Felipe III, Madrid, 2007-2008, 4 vols.

3 Sobre la economía de la gracia y el concepto de remuneración de servicios véase la última aportación de OLIVAL, F.: "La economía de la merced en la cultura política del Portugal Moderno", en ARANDA PÉREZ, F. J. - RODRIGUES, J. D. (Eds.): De Re Publica Hispaniae. Una vindicación de la cultura política en los reinos ibéricos en la primera modernidad, Madrid, 2008, pp. 389-407. 
Quien servía a los monarcas, al rey y a la reina, en su proximidad, quien tenía contacto cotidiano y directo con cualquiera de los dos soberanos, se podía ver favorecido por una serie de privilegios muy superiores a los que podían disfrutar otros servidores regios. Lo hemos demostrado por extenso para el caso de las Guardias Reales en el siglo XVIII, ese "ejército cortesano" que funcionó como un cuerpo autónomo en el conjunto del ejército y que gracias a esa proximidad a los monarcas gozó de un estatuto jurídico especial y logró copar los principales empleos del generalato 4 .

En concreto, en los siglos XVII y XVIII, los servidores y servidoras de palacio se vieron privilegiados por dos tipos de gracias regias especiales. La primera de ellas venía a institucionalizar la herencia como mecanismo de acceso a los oficios de palacio mediante el recurso a la concesión de los denominados "pasos de oficios", esto es, mercedes que facultaban a los titulares de un oficio a transmitirlos a un familiar, casi siempre un hijo o, en caso de no tener sucesión masculina, a un yerno, e incluso al marido de una sobrina. Cuando aludimos a la patrimonialización de los oficios cortesanos por determinadas familias, es preciso contextualizar ese proceso no como algo excepcional sino como una pauta regulada y convertida en práctica consuetudinaria, sustentada en el patronazgo regio que siempre procuraba rodearse de una clientela de servidores agradecidos por las múltiples gracias que dispensaba el monarca a quienes le servían en su inmediación. Como es obvio, desde la perspectiva del funcionamiento de las instituciones y de su eficacia, al igual que sucedía con las ventas de cargos, semejante práctica ha sido interpretada como una degradación de la administración pública ${ }^{5}$.

La segunda vía de la gracia regia, reservada de forma casi exclusiva también para servidores de palacio, consistió en la concesión de mercedes dotales para casar convenientemente a mujeres, ora fuesen ellas mismas servidoras de la Casa de la Reina, ora fuesen hijas o sobrinas de quienes desempeñaban puestos en la Corte. Sobre las mercedes dotales para mujeres, trataremos por extenso en las páginas siguientes. Por el momento, anotemos que en lo relativo a la provisión de oficios, las mercedes dotales se concedieron para el ejercicio de oficios en palacio pero sobre todo, de forma mayoritaria, para el desempeño de empleos en otros ámbitos institucionales de la monarquía, en concreto, magistraturas de justicia, plazas de consejero y, las más numerosas, plazas de contadores de la Contaduría Mayor de Cuentas.

4 ANDÚJAR CASTILlO, F.: "La Corte y los militares en el siglo XVIII”, en Estudis, 27, 2001, pp. 91-120; "La carrera militar en la España del siglo XVIII", en DEDIEU, J.P. - VINCENT, B. (Eds.): L'Espagne, l'État, les Lumières. Mélanges en l'honneur de Didier Ozanam, Madrid - Bordeaux, 2004, pp. 189-214.

5 DOMÍngUeZ ORTIZ, A.: Política fiscal y cambio social en la España del siglo XVII, Madrid, 1984 , p. 123. 
La remuneración de servicios cortesanos por medio de mercedes dotales constituyó, sin lugar a dudas, una de las máximas expresiones de un patronazgo regio que siempre consideró la administración del reino como patrimonio propio del monarca. Premiar el servicio con dotes para casar era un tipo de intercambio privilegiado, accesible tan solo para quienes se movían en las cercanías de los monarcas. De forma excepcional, las mercedes dotales se podían conceder a personas ajenas al servicio cortesano, cuando en los beneficiarios concurría algún mérito excepcional, o bien en aquellos momentos en que se vendían cargos y honores. En términos cuantitativos, con diferencia, la derrama de la gracia regia en forma de mercedes dotales, recayó mayoritariamente en beneficio de servidores de las Casas Reales y, a su vez, dentro de ellas, en las mujeres que servían en la Casa de la Reina.

Como su propio nombre indica, una merced dotal era una gracia particular que el rey concedía a una mujer u hombre que le había servido en su proximidad. En el caso de las mujeres se trataba de mejorar las condiciones de su propio casamiento y, en el de los hombres, el matrimonio de sus hijas, hermanas o sobrinas. Damas y camaristas, solían ser mujeres solteras, de familias nobles, que cuando casaban debían abandonar el servicio en palacio, momento en el que recibían la merced dotal que les permitía conseguir un ventajoso matrimonio al aportar al mismo un título honorífico, una renta - generalmente vitalicia-, o un empleo de la monarquía, en este último caso garantizando al futuro esposo un salario para toda la vida, la posibilidad de prosperar en la institución en la que ingresaba y el prestigio correspondiente al empleo que obtenía ${ }^{6}$.

Siempre las beneficiarias eran mujeres que veían recompensados así sus propios servicios o los de sus familiares en cualquiera de los numerosos cargos palaciegos. Se enmarcaban pues, las mercedes dotales, en una estrategia en la que, como acertadamente ha señalado María Victoria López-Cordón, el acceso inmediato a los soberanos, el desempeño de cargos palatinos, junto con el parentesco, sirvió como un instrumento para monopolizar tanto la confianza real como sus mercedes, y suplir así lo que el linaje, los blasones y el prestigio heredado no aportaban a algunas de las trayectorias individuales de los principales cuadros de la administración ${ }^{7}$. Al mismo tiempo, las mercedes dotales eran una parte fundamental del amplio cúmulo de gra-

6 La necesaria vinculación entre servicio en palacio y estado de soltería para damas y camaristas tan sólo se alteró a partir de 1712 cuando, con motivo de la reorganización de la casa de María Luisa de Saboya, se estableció que desde entonces la reina pudiese servirse de "damas casadas y que estas sean vasallas de la primera calidad, estimación y confianza para que se halle asistida con el decoro y decencia que es justo". Cfr. LÓPEZ-CORDÓN CORTEZO, Ma V.: "Entre damas anda el juego: las camareras mayores de Palacio en la edad moderna", en Cuadernos de Historia Moderna, Anejo II, 2003, p. 137.

7 LÓPEZ-CORDÓN CORTEZO, M ${ }^{\mathrm{a}}$ V.: "Definición social y estrategias matrimoniales en la España del siglo XVIII”, en MARTÍNEZ RUIZ, E. (Coord.): Vínculos y sociabilidades en España e Iberoamérica, siglos XVI-XX, Ciudad Real, 2005, p. 57. 
cias que garantizaban la conservación de los grupos familiares bajo la protección regia $^{8}$. Dispensándolas, el monarca conseguía para sus criados y criadas un matrimonio "de mayor conveniencia", y que quien le había servido tuviese un status económico y consideración social acorde con los puestos desempeñados en palacio. Al mismo tiempo, las mercedes dotales funcionaban también como un instrumento más de refuerzo de los vínculos de las beneficiarias -y, por matrimonio, de los beneficiarioscon la persona del soberano, propietario en última instancia de todos los empleos y de la dispensa de toda suerte de gracias ${ }^{9}$.

Por el momento no disponemos de una cronología precisa acerca del inicio de esta práctica de recompensas a los servidores de palacio, aunque ya a comienzos del siglo XVII aparecen las primeras críticas a un sistema que permitía "nombrar" para importantes empleos de la monarquía a individuos que no tenían más mérito que el haber casado con las portadoras de estas mercedes ${ }^{10}$. Su final sí que es más preciso, pues se sitúa en torno al año 1751, momento en que se concede la última merced dotal para ejercer una plaza de consejero ${ }^{11}$.

En cuanto a su tipología, es preciso diferenciar entre las mercedes dotales "pecuniarias", las meramente "honoríficas" -fundamentalmente hábitos de las órdenes militares y títulos nobiliarios-, las "mercedes de empleos" y un grupo, en principio minoritario, y más difícil de estudiar, el de "mercedes dotales venales".

En las páginas que siguen nos ocuparemos del tercer grupo, el de las "mercedes dotales de empleos", pues tanto las "pecuniarias" como las "honoríficas" -en espe-

8 GÓMEZ-CENTURIÓN JIMÉNEZ, C. y SÁNCHEZ BELÉN, J,A.: "La hacienda de la Casa del Rey durante el reinado de Felipe V", en La herencia de Borgoña. La hacienda de las Reales Casas durante el reinado de Felipe V, Madrid, 1998, p. 52. En este sentido, el papel desempeñado por las camareras mayores en la obtención de mercedes dotales ha sido también puesto de relieve por LÓPEZ-CORDÓN CORTEZO, Ma V.: "Entre damas anda el juego...", p. 138.

9 BRAVO LOZANO, J.: “Gracia y merced en época de desgracias. Cámara y vida cotidiana en el reinado de Carlos II", en BRAVO LOZANO, J. (Ed.): Espacios de poder: Cortes, ciudades y villas ( $S$. XVI-XVIII), Madrid, 2002, T, I., p. 113.

10 Ya las ordenanzas del Consejo de Hacienda de 1602 establecían que las plazas de contadores de la Contaduría Mayor de Cuentas no se pudiesen vender ni traspasar "ni se den en dote", según recordaba una consulta del mismo Consejo de Hacienda elevada al rey en febrero de 1618 con motivo de la concesión de una plaza de contador como merced dotal. AGS, Consejo y Juntas de Hacienda, Leg. 555.

11 Que sepamos, la última merced dotal de consejero es la otorgada en 1751 a José Gómez Terán, marqués de Portazgo, para quien casare con su nieta Manuela Terán (AHN, Consejos, Lib. 737). Con posterioridad a ésta se registra una de escaso valor, la merced dotal honorífica de "secretario del rey", concedida en 1756 a Francisco Antonio Salcedo Tapia por su matrimonio con María Teresa Cuadros, a cuyo marido se le había prometido una plaza de ayuda de cámara por merced dotal (AGS, Gracia y Justicia, Lib. 317). En el ámbito de los honores, también la última merced dotal se registra en el reinado de Fernando VI, quien concedió a Diego Bartolomé Adorno un Título de Castilla para quien casare con su hija María Agustina Adorno. Por su matrimonio con Manuel Negrete Torre, hizo a éste marqués de Torremanzanal en 1760 (AHN, Consejos, Lib. 684). 
cial los hábitos de las órdenes militares- precisarían de sendos estudios monográficos, dada la importancia que adquirieron durante los siglos XVII y XVIII. No obstante, algunas notas generales se pueden perfilar para establecer de forma más precisa sus elementos diferenciadores respecto a las "mercedes de empleos". Estrechamente relacionadas con esas tres tipologías, se hallarían las que hemos denominado como "mercedes dotales venales", que se concedieron en las mismas coyunturas en las que las necesidades de la hacienda obligaron a vender toda suerte de empleos. Dada su vinculación con las "mercedes de empleos", serán objeto de un apartado especial que permita diferenciar unas de otras.

Las "mercedes dotales pecuniarias" suponían la concesión de una dote en dinero a una mujer, bien con una sola cantidad fija para su casamiento, bien con carácter anual mientras viviese. Ya las Cortes de 1628 habían puesto como condición para la concesión del impuesto de millones que se redujesen "las mercedes que por vía de dote o de otra manera se hacían a las damas de Palacio" por importe de un millón de maravedíes, cuando se casaran Grande o hija de Grande, y de medio millón cuando se tratase de gentilhombres de cámara ${ }^{12}$. En los años siguientes las mercedes pecuniarias no sólo se mantuvieron sino que se incrementaron. Basta con echar una ojeada a la documentación de hacienda que conserva el Archivo General de Palacio de Madrid en la que se encuentran mercedes dotales consignadas sobre los "efectos de la Real Cámara" en las postrimerías del siglo XVII ${ }^{13}$.

Tratándose de mercedes vitalicias que suponían cargas anuales sobre la hacienda del rey, su extensión significó un enorme lastre para la hacienda de las Casas Reales que anualmente debían afrontar unos pagos que solían consignarse sobre su propio presupuesto. Por tanto, la alternativa menos gravosa a las mercedes dotales pecuniarias consistía en otorgar un mayor número de mercedes en forma de honores y cargos que no comportaban gravamen alguno para la hacienda real, pues los segundos, los cargos, en caso de no existir vacantes, se podían conferir como plazas super-

12 DOMÍNGUEZ ORTIZ, A.: "Los gastos de Corte en la España del siglo XVII", en Crisis y decadencia en la España de los Austrias, Barcelona, 1969, pp. 83-84.

13 Archivo General de Palacio (en adelante AGP), Reinados, Felipe V, Leg. 320. El día 1 de enero de 1693, Ana y Josefa Cortés, hijas de Simón Cortés, ayuda de la Real Botica, recibieron 100 ducados anuales de renta para "ayuda a que tomen estado"; Catalina Crota, esposa de Felipe Torres, ayuda de cámara de Carlos II, comenzó a percibir 500 ducados anuales en concepto de merced dotal; Eugenia Villegas, hija del secretario del rey Francisco Villegas, recibió una merced el 15 de julio de 1694 de 200 ducados anuales en "atención a los servicios de su padre y por haber muerto su hermana Teresa Villegas" quien gozaba de la Cámara de 3.700 reales al año; Francisca Petronila Marañón, hija de Juan Francisco Marañón, ayuda de cámara de Carlos II, comenzó a percibir desde enero de 1685 la cantidad de 1.000 ducados anuales para su casamiento con Juan Félix Manzano; por último, Juan Manuel Cearrote, que había servido la sumillería de corps, puso en 1697 en cabeza de su sobrina María Catalina Enríquez Cearrote una merced de 3.700 ducados al año, de los cuales se le había hecho merced "por vía de dote" por haber ejercido la citada sumillería. 
numerarias que tan sólo se comenzarían a servir -y por ende a percibir el salario sus titulares- desde el momento en que se produjese una "vacante del número".

Entre las "mercedes honoríficas" más preciadas destacan los hábitos de las órdenes militares y los títulos nobiliarios. Elena Postigo demostró que en el reinado de Felipe IV el 4,8\% de los hábitos fueron a parar a los que desempeñaban oficios de la Casa Real, pues se utilizaron como un medio de pago para compensar la política de reducción de gastos propugnada por Olivares ${ }^{14}$. Aunque no contamos con estudios sistemáticos para los años siguientes, los escasos disponibles demuestran que la demanda de hábitos para dotar mujeres se mantuvo muy activa a lo largo del siglo XVII ${ }^{15}$. Entre la documentación de los denominados "pasos de hábito", o transferencia de títulos concedidos a una persona para otra, se encuentran mercedes dotales de caballeros de las diversas órdenes militares ${ }^{16}$. Incluso, alguna encomienda formó parte del mismo juego ${ }^{17}$.

Del mismo modo, hubo Títulos de Castilla que sirvieron para dotar el matrimonio de mujeres que servían en importantes puestos de la Corte. Práctica extendida, como mínimo desde el reinado de Felipe IV, algunas damas de las reinas hicieron marqueses o condes a quienes casaron con ellas. A modo de ejemplo, señalemos el caso de Pedro de Navarra que se tituló como marqués de Cabrega en 1654 merced a su matrimonio con Antonia de Borja de Urrea, dama de la reina, que aportó dicho título a su casamiento ${ }^{18}$; unos años después, en 1660, Alonso Fernández Manrique logró titularse como conde de Montehermoso por su matrimonio con Luisa María Carvajal, dama de la reina, a quien Felipe IV le había concedido una merced dotal para casar ${ }^{19}$. Igualmente en el siglo XVIII se prolonga la misma práctica. Sirve de ejemplo el título de marquesa de Liseda, concedido en 1711 -sacado en 1718- a Isabel Moctezuma, dama de la reina Mariana de Neoburgo, para casar con Juan Manuel Orense del Castillo, hijo del vizconde de Amaya, alférez mayor de Burgos ${ }^{20}$.

14 POStigo CAStellanos, E.: Honor y privilegio en la Corona de Castilla. El Consejo de las Ordenes y los Caballeros de Hábito en el siglo XVII, Soria, 1988, p. 120.

15 WRIGHT, L.P.: "Las Órdenes Militares en la sociedad española de los siglos XVI y XVII. La encarnación institucional de una tradición histórica" en ELLIOTT, J. H.(Ed.): Poder y sociedad en la España de los Austrias, Barcelona, 1982, p. 35.

16 Diversos casos de títulos de caballeros de hábito obtenidos por mercedes dotales se encuentran en AHN, Ordenes Militares, Leg. 217.

17 Así, por ejemplo, en agosto de 1705 Luis Joaquín Rubí Bracamonte, marqués de Fuente El Sol, obtuvo la futura de la encomienda de Almuradiel, en la orden de Calatrava, por su matrimonio con la dama de la reina María Pimentel, a quien se le había concedido en calidad de merced dotal. AHN, Ordenes Militares, Lib. 221.

18 AHN, Consejos, Leg. 13.207.

19 AHN, Consejos, Leg. 11.716.

20 AHN, Consejos, Leg. 13226. 
Por lo que hace a las "mercedes dotales de empleos", la mayoría remuneraron igualmente a servidores y servidoras de palacio. La importancia de esos empleos estuvo directamente relacionada con la relevancia del puesto que se había desempeñado en palacio, si bien es preciso diferenciar entre las mercedes concedidas a mujeres y a hombres. Las primeras, se solían conceder a damas y camareras de las reinas cuando abandonaban el servicio en palacio para casar. De este modo, mejoraban sustancialmente sus expectativas matrimoniales al portar una merced dotal por la que el rey convertía al futuro marido en consejero de Hacienda o Indias, en oidor de un tribunal de justicia o en contador de alguna de las múltiples contadurías del Consejo de Hacienda. Una segunda vía, de menor relevancia, en cuanto a la "dote" proporcionada por el monarca, se documenta en las mercedes dotales -fundamentalmente contadurías- concedidas a servidores de palacio que mejoraban así el matrimonio de sus hijas, hermanas o sobrinas. Entre la nómina de beneficiarios que habían servido a las reinas se encuentran numerosos empleos, entre otros, los de aposentador, repostero, jefe de la frutería, conserje de real sitio, cochero de caballeriza, ayuda de cámara del rey, etcétera.

Las mercedes dotales, concedidas con carácter vitalicio, se podían utilizar mientras que viviese la adjudicataria. En caso de enviudar, las mujeres podían casar de nuevo y, por tanto, hacer oidor, contador o consejero a su nuevo esposo, o bien, reclamar una pensión vitalicia por el puesto desempeñado por su difunto marido. Por lo general, optaron por esta segunda vía, pero también se encuentran casos como el de Carolea Marbán, hija del secretario de la reina Mariana de Austria, Eugenio Marbán, cuyos avatares en torno a la merced dotal que se le concedió de alcalde mayor de la Audiencia de Galicia constituye uno de los mejores ejemplos de la arbitrariedad que presidía este sistema de provisión de cargos. En noviembre de 1697, Carolea casó con Pedro Muñoz Castilblanque, convirtiéndolo así en alcalde mayor de la Audiencia de Galicia, pero unos meses después falleció, justo cuando Carolea había conseguido que se le permutase dicha merced dotal por una plaza del alcalde del crimen de la Chancillería de Valladolid. En el mes de agosto de 1699 volvió a casar de nuevo, esta vez con Álvaro Villegas, un colegial de San Bartolomé de la Universidad de Salamanca que consiguió así la alcaldía del crimen del tribunal vallisoletano, en calidad de supernumerario, a la espera de que se produjese una vacante del número ${ }^{21}$. Más excepcional resulta el caso de Teresa Alemán, dama de la reina Mariana de Austria, quien en 1681 recibió como merced para casar un empleo de Procurador General de la Orden de Santiago, en régimen de futura, pues en ese momento estaba ocupado por otra persona. Su esposo, Andrés Antonio de Riaño, no pudo ejercer ese cargo, pues falleció

21 AHN, Consejos, Lib. 731 y 732. 
en 1691 cuando aún no había cesado en su desempeño el anterior titular. Dado que Teresa Alemán, no había disfrutado de los salarios correspondientes al empleo con que había sido dotada, consiguió que la merced dotal la disfrutase su hermano Alonso Antonio Alemán, quien desde esa fecha pasó a ejercer como Procurador General de la citada orden ${ }^{22}$. Ya viuda, Teresa Alemán volvería de nuevo a palacio para servir como camarista de la reina María Luisa de Saboya, primera esposa de Felipe V.

\section{Las mercedes dotales "venales"}

Las "mercedes dotales venales" constituyen un grupo diferenciado por su propio origen y por su concesión de forma más episódica. Podemos identificarlas cuando comprobamos que ni las mujeres beneficiarias de las mismas ni sus padres presentaban un aval de servicios cortesanos, ni tampoco tenían un mérito especial que justificara la obtención de semejantes gracias. Hasta la extinción de las mercedes dotales a mediados del siglo XVIII, constatamos dos datos inequívocos: primero, que se pudieron adquirir con dinero en los mismos períodos en que se desarrollaron operaciones venales durante el reinado de Felipe V, esto es, entre 1704 y 1711 para financiar la Guerra de Sucesión, y en los años cercanos a la suspensión general de pagos de 1739; en segundo lugar, que se concedieron para que los cónyuges las ejercieran en las mismas instituciones en que esos puestos eran objeto de venalidad, esto es, en los Consejos de Hacienda e Indias, magistraturas de las Chancillerías y Audiencias y, en su gran mayoría, en la Contaduría Mayor de Cuentas.

De la etapa venal de 1704-1711, un análisis diferenciado de las concedidas por dinero y las que, en teoría, correspondían a simples gracias regias, permite clarificar el doble origen de este tipo de mercedes. En el ámbito de la justicia, hemos documentado la concesión de un total de seis mercedes dotales en los años que transcurren entre 1706 y 1711. Finalizada esta etapa venal, se interrumpe por completo su concesión, y desde entonces no se registra hasta el año 1732 una nueva gracia de este tipo para servir una plaza de oidor. Más decisivo resulta el hecho de que, analizados los méritos de aquellas mujeres que obtuvieron mercedes dotales, no encontremos en ninguno de los casos vinculación alguna de las portadoras de esos títulos o de sus padres y madres con las Casas Reales. Incluso, en uno de los casos, el de Alonso Rico Villarroel, que según los libros de la Cámara se le dio plaza de oidor de la Chancilleria de Valladolid por su boda con María Antonia Valderrama Haro, sabemos que en el mismo mes que obtuvo el puesto, mayo de 1706, ingresó en la Tesorería Mayor 90.000 reales, que los entregó “en virtud de orden de la reyna nuestra señora” pero

22 AGS, Dirección General del Tesoro, Inv. 2, Leg. 4. 
sin especificar el concepto de dicho pago $^{23}$. Ese fue el origen de la merced dotal, pues el padre de la esposa, García Valderrama, era a la sazón oficial mayor de la Secretaría de Milán del Consejo de Italia ${ }^{24}$.

Más interesante resulta el caso de Francisco Ventura Esquivel, que obtuvo su plaza de oidor de Valladolid en marzo de 1709 por casamiento con una hija de Bernardo Solís, escribano de la Cámara de Castilla, y por tanto sin "mérito especial" como para haber recibido semejante gracia regia. Conocedor del mercado que estaba abierto en la Corte desde hacía años, Esquivel, en mayo de 1711, se procuró un ascenso a fiscal de la sala de Alcaldes de Casa y Corte al pagar 24.000 reales y dejar a beneficio de la real hacienda su plaza vallisoletana de oidor, la misma que había conseguido un poco antes, supuestamente, como simple merced dotal ${ }^{25}$. En un informe del año 1725 para terna de ascenso a fiscal del Consejo de Hacienda se dudaba acerca de si la plaza por la cual había accedido a la carrera judicial la había obtenido "por casamiento o por compra", al tiempo que se consideraba que la había servido "sin demostración de literatura"26.

El repaso de las restantes mercedes dotales concedidas entre los años 1704 y 1711 para ejercer magistraturas de justicia, no revela coincidencia alguna entre las agraciadas y el ejercicio de cargos palatinos por parte de ellas mismas o de sus familiares. Así, Marcos Corona, abandonó en julio de 1708 su puesto de juez de apelaciones de la Audiencia de Canarias para servir una plaza de oidor de la Chancillería de Granada tras casar con una hija de Luis Curiel, a la sazón fiscal del Consejo de Castilla $^{27}$; Pedro Rosales Medrano logró en 1710 una alcaldía de los hijosdalgo de la Chancillería de Valladolid por su matrimonio con Dionisia Juana Corral, quien al parecer poseía la merced por concesión a su abuelo Diego del Corral28; Juan Miguel Marín Fajardo consiguió en junio de 1709 plaza de oidor de la Chancillería de Granada por su matrimonio con Ana de Salamanca, hija de Miguel de Salamanca, corregidor de Ronda, muerto de forma violenta durante el ejercicio de su cargo ${ }^{29}$; Alonso Yáñez obtuvo su plaza de alcalde del crimen de la Chancillería de Valladolid en 1711 por su casamiento con Manuela Abaunza Merino, nieta de Clemente Merino ${ }^{30}$,

23 ANDÚJAR CASTLLO, F.: Necesidad y venalidad. España e Indias, 1704-1711, Madrid, 2008, p. 165.

24 AGS, Dirección General del Tesoro, Inv. 2, Leg. 4.

25 ANDÚJAR CASTILLO, F.: Necesidad y venalidad..., p. 165.

26 Ibídem, p. 165.

27 AHN, Consejos, Lib. 733.

28 AHN, Consejos, Lib. 733. En un informe de 1729 inserto en una terna de la Cámara se señalaba, según informes reservados, que había salido "por casamentero" a la plaza que seguía ocupando en la sala de los hijosdalgo de la Chancillería de Valladolid. AGS, Gracia y Justicia, Leg. 140.

29 GÓMEZ GONZÁLEZ, I.: La justicia, el gobierno y sus hacedores. La Real Chancillería de Granada en el Antiguo Régimen, Granada, 2003, p. 128.

30 AHN, Consejos, Lib. 733. 
que había sido propietario perpetuo - por compra- del puesto de Alguacil Mayor del Consejo de Hacienda; por último, Juan de Feloaga, hijo del marqués de Navahermosa, consiguió una plaza de oidor de la Chancillería de Granada en 1714 cuando casó con Rosolea López Zárate, hija del marqués de Villanueva de la Sagra, a la cual se le había concedido en enero de 1708 una merced dotal de oidor de cualquiera de las dos Chancillerías "por los méritos de su tío, el marqués de la Florida”, según publicitó la Gaceta de Madrid $^{31}$. En este último caso, como en los demás, no se aprecian especiales servicios en la Corte ni de las beneficiarias de las mercedes ni de sus familiares. En concreto, el citado marqués de la Florida, en el momento de la obtención de la merced era coronel del regimiento de caballería de Órdenes Viejo.

Merece individualizarse el caso de Ana de Salamanca, en cuanto que representa la excepcionalidad de una merced dotal que debió recibir por "dos vidas". Como se ha señalado, por casar con ella, Juan Miguel Marín Fajardo fue nombrado oidor de Granada en 1709, falleciendo en el año 1732, cuando había ascendido ya hasta fiscal del Consejo de Órdenes Militares. En esa misma fecha su hija, Josefa Marín, heredó la merced dotal de su madre, y casó con Melchor del Ollo Bazán, a quien lo hizo alcalde del crimen de la Chancillería de Granada, cargo que pudo disfrutar por poco tiempo, pues falleció en marzo de $1734^{32}$. Sin méritos especiales, sin que la gracia procediese del ejercicio de un cargo en la proximidad del rey, y obtenida en un período de venta de cargos, la concesión de una merced dotal hereditaria de magistrado induce a considerar que en el origen de la misma debieron incidir otras razones ajenas a aquella muerte violenta que sufriera el corregidor de Ronda, Miguel de Salamanca.

Fuera del ámbito de la justicia se reproduce el mismo esquema, pues se documentan algunas mercedes dotales en las que interviene el dinero. En marzo de 1710 Andrés Llamas Ortiz, un oficial de la Secretaría del Perú del Consejo de Indias, recibió una merced de contador del título de la Contaduría Mayor de Cuentas para dotar a su hermana María. Así consta en los registros de la Dirección General del Tesoro ${ }^{33}$. Sin embargo, entre los ingresos contabilizados en el Tribunal Mayor de Cuentas se precisa que, además, por esa merced había pagado 6.000 reales para las "urgencias" que la monarquía tenía en aquella coyuntura ${ }^{34}$.

Una variante, más inusual, se documenta en la concesión de una merced dotal a un servidor de palacio con facultad de transferirla - "beneficiarla"- a otra persona,

31 Gaceta de Madrid, 17 de enero 1708.

32 AHN, Consejos, Lib. 736.

33 AGS, Dirección General del Tesoro, Inv. 13, Leg. 2, Exp. 7.

34 AGS, Tribunal Mayor de Cuentas, Leg. 1880. De esa misma tipología venal es la merced de una plaza del tribunal de la Cámara de Comptos de Navarra comprada en 1710 por 30.000 reales para quien casare con una hija suya. AGS, Estado, Leg. 7837. 
de tal modo que lo que recibiría sería el producto de su valor. Aunque se trata de una “merced dotal honorífica", es el caso de María Agustina Sarmiento, dama de la reina, quien en octubre de 1689 recibió una merced dotal de un Título de Castilla con facultad de beneficiarlo en la persona que quisiere. Por este medio, Carlos II le estaba concediendo 22.000 ducados, precio en que por entonces estaba tasado un Título de Castilla. Por tanto, María Agustina aportó a su boda un caudal cercano a esa cifra, pues en agosto de 1690 hizo uso de la merced al venderla a Manuel González de Castañeda, quien desde entonces se tituló como marqués de la Villa de Alcázar ${ }^{35}$.

Un caso excepcional de merced dotal que parece tener origen en el dinero más que en otros méritos, se documenta en la concedida en 1713 de contador de la Contaduría Mayor de Cuentas a Antonia Velasco Angulo, que acababa de enviudar de Antonio Sanguineto, marqués de San Antonio de Miralrío, quien había sido corregidor de Madrid y agraciado con ese título nobiliario por los méritos contraídos durante la ocupación de Madrid por parte de las tropas austracistas. ${ }^{36}$ La merced, según la documentación, la recibía en remuneración de los servicios de su marido, quien, por otro lado, ya había sido remunerado con el título nobiliario por esos mismos servicios. Cuando aún no había firmado capitulación matrimonial alguna, Antonia Velasco comenzó a percibir la mitad del sueldo de su merced dotal, pero en agosto de 1715, sin tener mérito adicional ni servicio que lo justificase, consiguió una notable mejora en su merced al ser sustituida por otra dotal de consejero del Consejo de Hacienda. Permaneció viuda durante largo tiempo, y en 1727 consiguió una interesante permuta de esta última merced, pues a cambio de cederla a la real hacienda y en recompensa también de los asientos hechos con la "Tesorería General de Cruzada", se le concedió el título de marquesa de Perales del Río ${ }^{37}$. En el origen de estas mercedes dotales parece estar una considerable fortuna por parte de Antonia Velasco y Angulo, probablemente heredada de su padre, Juan de Velasco y Angulo, quien había sido contador del Consejo de Indias. De hecho, dos años después de titularse como marquesa, casó con otro importante financiero de Felipe V, Ventura de Pinedo, a la sazón Director de la Renta del Tabaco, pero con anterioridad experto intermediario en la compraventa de cargos públicos ${ }^{38}$.

Por último, en el mismo apartado de las mercedes dotales venales, aunque con un carácter y origen muy distinto al que venimos tratando, se podrían considerar algunas compras de empleos para servir en Indias que no se adquirieron para ser ejercidos por los propios compradores sino para dotar el casamiento de alguna hija. Sirve de

35 AHN, Consejos, Leg. 8975, Exp. 23.

36 AGS, Dirección General del Tesoro, Inv. 24, Leg. 117.

37 AHN, Consejos, Leg. 8977.

38 Sobre Ventura de Pinedo véase, ANDÚJAR CASTILLO, F.: Necesidad y venalidad..., pp.109-111. 
ejemplo, entre otros muchos casos, el de Pedro Bermúdez Becerra, quien compró en junio de 1711 por 120.000 reales una plaza de contador mayor del juzgado de bienes de difuntos del distrito de Quito para la persona "que casase con una de sus hijas", con facultad de que mientras se producía ese matrimonio se pudiese servir la plaza por teniente, es decir, por una persona interina que actuara en nombre del propietario ${ }^{39}$.

\section{Sobre la transmisión de los oficios en palacio}

A pesar de que no contamos con estudios monográficos sobre los mecanismos de concesión y transmisión de oficios de las Casas Reales, entre los escasos disponibles $^{40}$, los publicados por Elena Serrano García sobre la Caballeriza de la Reina en los reinados de Carlos II y Felipe V, permiten interpretar el sentido que tuvieron las mercedes dotales en el seno de los cargos palatinos ${ }^{41}$. La autora señala que los oficios jurados de la Caballeriza de la Reina, los de provisión regia directa, venían a ser mercedes reales que dependían por completo de las relaciones de parentesco establecidas en la propia Caballeriza, en donde las mismas familias se sucedían en los mismos cargos durante generaciones. Los oficios de palacio eran en la práctica "propiedad de los titulares", y transmisibles por herencia mediante la obtención de mercedes regias que permitieran transmitirlos como bienes patrimoniales ${ }^{42}$.

En la Caballeriza de la Reina, así como en otras dependencias de palacio, lo que realmente se produjo fue un proceso de patrimonialización de los cargos por parte de una serie de familias, producto tanto de la obtención de mercedes dotales como de "derechos de paso" que posibilitaban esa transmisión hereditaria de los oficios como

39 AHN, Estado, Leg. 595-1.

40 Vid. al respecto los estados de la cuestión publicados por VÁZQUEZ GESTAL, P.: El espacio del poder: la corte en la historiografía modernista española y europea, Valladolid, 2005; "La corte en la historiografía modernista española. Estado de la cuestión y bibliografía", en Cuadernos de Historia Moderna, 2003, Anejo 2, pp. 269-310.

41 SERRANO GARCÍA, E.: "Los empleos en la caballeriza de la reina durante el reinado de Carlos II: mecanismos de transmisión”, en Anuario de Historia del Derecho Español, LXIII-LXIV, 19931994, pp. 1041-1064; SERRANO GARCÍA, E.: "El acceso a los oficios de la caballeriza de la reina en tiempos de Felipe V: relaciones familiares”, en CASEY, J. - HERNÁNDEZ FRANCO, J. (eds.): Familia, parentesco y linaje, Murcia, 1997, pp. 375-376.

42 La transmisión por herencia de los oficios en la Corte estaba ya vigente desde el siglo XVI. Cfr. MARTÍNEZ MILLÁN, J.: “La crisis del 'partido castellano' y la transformación de la Monarquía Hispana en el cambio de reinado de Felipe II a Felipe III", en Cuadernos de Historia Moderna, 2003, Anejo II, p. 22. Igualmente se sabe que algunas varas de alguaciles de Casa y Corte concedidas en el siglo XVII a nodrizas se daban por juro perpetuo de heredad para "poner en estado" a sus hijas. Cfr. MONTAGUT, E.: "Criadas y nodrizas en la Casa Real. Sus recompensas: varas de alguaciles de Casa y Corte", en Torre de los Lujanes, 20, 1992, p. 87. 
mejor garantía de fidelidad, lealtad y buen servicio a las personas reales ${ }^{43}$. Cuando la transmisión del oficio carecía de línea masculina para garantizar la continuidad, el "paso" del oficio solía hacerse en calidad de merced dotal a favor de una hija, hermana o sobrina del titular, e incluso el rey podía conceder la facultad de transmitirlo por vía de venta ${ }^{44}$. Además, la merced dotal servía para reforzar el poder de las redes familiares en los empleos de palacio cuando conseguían "colocar" a sus yernos en puestos que no requerían acreditar más mérito que la cédula con la que el monarca dotaba a una mujer para su casamiento.

En diferentes ámbitos de la Corte se observan las mismas prácticas. En septiembre de 1704, el ujier de cámara Manuel Sánchez Arce consiguió el derecho de paso de su empleo para quien casare con su sobrina Josefa Fernández. Unos años después, en noviembre de 1711, Josefa casó con Andrés García Navaja y, en virtud de tal matrimonio, pasó a ocupar el empleo concedido al tío de su esposa en 170445. En 1709 quien consiguió otra plaza dotal de ujier fue Ignacio Urruela al casar con María Josefa López Suárez, a quien se le había concedido por los servicios de su padre como contralor de la reina Mariana de Neoburgo ${ }^{46}$. En el seno de su propia familia transmitió en 1724 Nicolás José Herrera Vaca su oficio de guardajoyas de la Real Casa, al obtener una merced dotal para "pasar" su empleo en quien casare con su hija ${ }^{47}$.

La patrimonialización de los empleos palaciegos se puede constatar de forma más clara aún cuando se comprueba que algunas mercedes dotales que, en principio, eran vitalicias, se llegaron a transmitir por herencia. En 1696, Francisco Pizarro, marqués de San Juan, mayordomo y primer caballerizo de la Reina, recibió una plaza de consejero supernumerario del Consejo de Hacienda por su boda con una dama de la reina madre, Isabel Rubín de Celis ${ }^{48}$. En principio era una plaza supernumeraria, que no pudo hacer efectiva hasta agosto de 1715, fecha en la que comenzó a ejercer una plaza del número. En 1727 se jubiló como consejero de Hacienda y solicitó a Felipe $\mathrm{V}$ que la merced dotal que gozaba se le permutase por otra merced de consejero y camarista de Indias para su hijo primogénito, Juan Pizarro. A pesar de la desproporcionada demanda, en diciembre de aquel mismo año el rey accedió a nombrar con-

43 A veces para conseguir esos "derechos de paso" era preciso abonar una determinada cantidad de dinero para allanar así posibles dificultades.

44 Según Eduardo Montagut muchas varas de alguaciles de Casa y Corte que se daban como mercedes dotales en el siglo XVII se acabaron convirtiendo en dinero en metálico pues los peticionarios solicitaban venderlas para aplicar su producto a la dote matrimonial. Cfr. en MONTAGUT, E.: Op. cit., p. 86 y ss.

45 AGP, Reinados, Felipe V, Leg. 312.

46 AGP, Reinados, Felipe V, Leg. 291-2.

47 AGS, Gracia y Justicia, Lib. 316.

48 AGS, Dirección General del Tesoro, Inv. 13, Leg. 1, Exp. 3. 
sejero de Indias a su hijo, cargo que acumuló al de caballerizo de la reina que había heredado de su padre ${ }^{49}$.

Las consideraciones antecedentes ponen de manifiesto la necesidad de profundizar en el análisis de los mecanismos de transmisión de los oficios en la Corte. Es imprescindible -máxime para el siglo XVIII en el que se ha otorgado todo el protagonismo del poder a los Secretarios del Despacho- analizar el papel de los denominados "jefes de palacio" y otros servidores próximos a los monarcas, cual lo han hecho Carlos Gómez-Centurión para los sumilleres de Corps ${ }^{50}$, y María Victoria LópezCordón para las camareras mayores que en apariencia tuvieron menor poder orgánico pero que disfrutaron de una enorme capacidad de influencia ${ }^{51}$.

El rey, fuente de toda gracia, recompensó a sus criados de múltiples formas que solían ir más allá de la percepción del mero salario mensual. El monarca podía distribuir favores a su libre albedrío sin límite alguno, pues la liberalidad regia era tan infinita como que el peso de lo arbitrario marcaba todo el proceso de decisión. Ejercer un empleo cerca del rey o de la reina siempre era garantía de que el manantial de mercedes, tarde o temprano, acabaría regando la casa de un individuo, de una familia, de un linaje. Por tanto, las mercedes para dotar mujeres con cargos del real servicio, tuvieron su principal espacio de distribución entre los propios cargos palatinos. Pero precisamente esa cercanía a las personas regias permitió a algunos criados reales beneficiarse de un doble proceso de reparto de prebendas, las que posibilitaban el ejercicio de cargos de palacio y las que servían para ocupar cargos en otros ámbitos de la administración.

\section{Mercedes dotales de empleos durante el reinado de Carlos II}

Algunos ejemplos relativos a mercedes dotales concedidas por Carlos II ilustran acerca del excelente horizonte que se abría para quienes servían cerca de las personas regias, en especial para quienes lo hacían en la Casa de la Reina: la camarera mayor, azafatas, dueñas de honor, damas, camaristas, dueñas de retrete y lavanderas, entre otras. Todas ellas, así como varones que también servían en palacio, en función de la importancia de los cargos desempeñados y de la proximidad a los monarcas -en especial a la reina- trataban de obtener destinos en la administración y gobierno de la monarquía que les asegurasen un conveniente casamiento. Los tres espacios principales en

49 AGS, Estado, Leg. 6380. Años más tarde, en concreto en 1741, sería nombrado sumiller de corps del rey.

50 GÓMEZ-CENTURIÓN JIMÉNEZ, C.: "Al cuidado del cuerpo del Rey: los sumilleres de Corps en el siglo XVIII”, en Cuadernos de Historia Moderna, 2003, Anejo II, pp. 199-239.

51 LÓPEZ-CORDÓN CORTEZO, Ma V.: "Entre damas anda el juego: las camareras mayores de Palacio en la edad moderna", en Cuadernos de Historia Moderna, Anejo II, 2003, pp. 123-152. 
los que se iban a conceder las mercedes dotales fueron las plazas de contadores de la Contaduría Mayor de Cuentas, las magistraturas de justicia -sobre todo las de las dos Chancillerías- y las plazas de consejero de los Consejos de Hacienda e Indias.

Las que con mayor prodigalidad se distribuyeron fueron las plazas de contadores de la Contaduría Mayor de Cuentas que, como veremos más adelante, casi siempre provocaron el rechazo del Consejo de Hacienda a semejante sistema de provisión. Dos contadurías especiales, por no ser de la Contaduría Mayor sino del Consejo de Indias -en el que tras la reforma de 1691 tan sólo ejercían cuatro contadores- se concedieron por merced dotal, una de ellas a Pedro Castro Colonna en 1691 "por causa onerosa de matrimonio", y otra en 1694 a Gabriel Francisco Ontañón por su matrimonio con Teresa de Biedma, camarista de la reina Mariana de Austria ${ }^{52}$. En el resto de las contadurías concedidas por mercedes dotales se encuentran como beneficiarios los más variados oficios de las Casas Reales. Así, por ejemplo, el repostero de la Casa de la Reina, Felipe Torres, consiguió en 1698, para quien casare con su hija Manuela Victoria, una merced dotal de contador de la Contaduría Mayor de Cuentas, que ejercería Diego Fernández Gala, quien hasta entonces servía como oficial entretenido de la contaduría de los libros de mercedes del Consejo de Hacienda ${ }^{53}$.

Las magistraturas de justicia, plazas de oidor, del alcalde del crimen y alcalde de los hijosdalgo de las dos Chancillerías, se concedieron por merced dotal debiendo acreditar los esposos de las portadoras haber cursado estudios de Derecho. Con tales mercedes se podía acceder directamente a un puesto de oidor sin haber pasado previamente por una alcaldía del crimen. Es el caso de Francisco Antonio Aguado quien accedió a la carrera judicial al conseguir en 1697, y a edad muy joven, una plaza de oidor de Sevilla por merced dotal. Ese fue el inicio de un cursus honorum brillante que culminó en 1729 como consejero de Castilla tras haber pasado por los Consejos de Indias y Hacienda. Unos años antes, también consiguió directamente una plaza de oidor Juan Cid Feijoo, al casar con María Alba, hija de Miguel Alba, médico del rey, a quien se le había concedido en calidad de merced dotal. Como muestra de mercedes dotales de alcaldías del crimen, se puede citar el caso de Isabe Zúpide Aponte, hija del doctor Zúpide de Vergara, médico de cámara de Felipe IV. En primeras nupcias casó con Antonio Barba Mazo, hijo de otro médico de Felipe IV, Pedro Barba ${ }^{54}$, y como portadora de una merced dotal de alcalde del crimen de la Chancillería de Valladolid posibilitó el ingreso de su marido en este tribunal en julio de 1678. Sin embargo, pronto enviudó,

52 AGI, Indiferente General, Leg. 480, Leg. 1.

53 AGS, Consejo Supremo de Hacienda, Leg. 185.

54 BARRIO MOYA, J. L.: "Don Pedro Barba, médico palentino del rey Felipe IV. Aportación documental”, en Publicaciones de la Institución Téllez de Meneses, 77, 2006, pp. 385-406. 
aunque pudo volver a usar la merced dotal, haciendo alcalde del crimen de la misma Chancillería a su nuevo marido, Manuel Morales Calderón ${ }^{55}$.

Este especial sistema de acceso a las magistraturas de justicia, por senda tan extraordinaria como la de la merced dotal, tuvo su aplicación más "grave" para el ejercicio de la justicia en la provisión de fiscalías, empleos que, dada su trascendencia para el buen funcionamiento de los tribunales, no fueron objeto de transacción cuando se produjeron enajenaciones de empleos de justicia ${ }^{56}$. Sin embargo, no se observó la misma práctica en relación a las mercedes dotales que, en el fondo, venían a ser un sistema de provisión muy similar al de las ventas de cargos, en tanto en cuanto respondían directamente al ejercicio del patronazgo regio, no a méritos en la carrera burocrática. En particular, la fiscalía del Consejo de Guerra se proveyó en diversas ocasiones como merced para dotar determinados casamientos. La primera que tenemos registrada para el siglo XVII, tuvo lugar en 1635, cuando se concedió una merced dotal para ejercer dicha fiscalía a la persona que casase con la hija de Cristóbal Benavente, consejero de Guerra y Embajador de España en Francia ${ }^{57}$. Otra fiscalía del Consejo de Guerra que se proveyó por merced dotal fue la concedida en 1694 a María Angulo, hija de Juan Angulo, Secretario del Despacho Universal. Dos años después contrajo matrimonio con Francisco Doriga, Catedrático de Vísperas de Cánones de la Universidad de Salamanca, quien obtuvo nombramiento de fiscal del Consejo de Guerra en régimen de futura al estar ocupado el puesto en el momento de su matrimonio ${ }^{58}$.

Por su parte, Tomás Jiménez Pantoja, consiguió en diciembre de 1675 una plaza de fiscal de la sala de Alcaldes de Casa y Corte por su matrimonio con Mariana Cuellar Losada, dama de la reina Mariana de Austria ${ }^{59}$. De este modo, a una edad muy joven, inició una excepcional carrera en la judicatura en la que pasó por los Consejos de Indias, Hacienda y Castilla, y que culminó como camarista de Castilla y gobernador del Consejo de Hacienda en $1706^{60}$. Otra fiscalía que también se proveyó por merced dotal, y que se volvería a conceder de nuevo por el mismo sistema en 1736, fue la de la Casa de Contratación, concedida en 1688 por su matrimonio con Juana Eugenia de Avilés a Juan de Sotomayor San Martín, quien poco tiempo después promocionaría a la fiscalía del Consejo de Hacienda ${ }^{61}$.

55 AHN, Consejos, Lib. 731.

56 ANDÚJAR CASTILLO, F.: Necesidad y venalidad..., p. 152.

57 AHN, Estado, Leg. 6403.

58 AGS, Dirección General del Tesoro, Inv. 23, Leg. 7

59 AHN, Consejos, Lib. 734.

60 AGS, Dirección General del Tesoro, Inv. 13, Leg. 7; AHN, Consejos, Lib. 731.

61 AGS, Dirección General del Tesoro, Inv. 2, Leg. 5. 
Entre las plazas de consejero otorgadas por merced dotal durante el reinado de Carlos II merecen reseñarse dos casos singulares, el de Tomás Antonio de la Cerda, marqués de Laguna de Camero Viejo, segundón del duque de Medinaceli, y el de Alejo Guzmán. El primero, Tomás Antonio de la Cerda, obtuvo en 1675 una plaza de consejero camarista de Indias por su matrimonio con María Luisa Manrique Gonzaga, dama de la reina. Además de la plaza de camarista, la esposa aportó al matrimonio una merced pecuniaria, por importe de 6.000 escudos, más otros 1.000 situados sobre el Real Bolsillo. Ante tan sustanciosa dote, la aportación del marido no quedó atrás, pues su hermano le entregó una notable fortuna para su boda: una suma de 100.000 ducados más una renta anual de 8.000 ducados en concepto de legítima ${ }^{62}$. La anómala provisión del cargo, sin ni siquiera haber sido antes consejero de Indias, debió servir tan solo para nutrir las ya de por sí sustanciosas rentas de la familia, pues el marqués de la Laguna de Camero Viejo siguió luego la carrera militar, desempeñando, entre otros puestos, el virreinato de Nueva España, para acabar culminando su trayectoria como mayordomo mayor de la Casa de la Reina Mariana de Austria. Por su parte, Alejo Guzmán consiguió en 1690 una plaza de consejero del Consejo de Italia por su matrimonio con Constanza Barradas Bazán, sobrina de la marquesa de Lanzarote, dueña de honor de la reina Mariana de Neoburgo, a quien le había sido concedida por la propia reina ${ }^{63}$.

Por último, una perspectiva más completa de los favores que se podían obtener en palacio, en forma de mercedes para servir cargos, se puede obtener a través de un análisis en clave familiar, tomando como referencia la extensa red de la familia Marbán, que se vio agraciada con múltiples mercedes dotales en las postrimerías del siglo XVII, concedidas todas ellas en torno a Eugenio Marbán y Mallea, quien hasta su muerte en junio de 1697 había desempeñado los puestos de secretario de la reina, ayuda de cámara del rey y secretario de cámara y de la Real Estampilla ${ }^{64}$. Eugenio Marbán situó a varias de sus hijas como camaristas de la reina, y lo propio hizo con su hermana Leonor, también camarista de la reina, quien obtuvo en 1656 una merced dotal de contador general de la razón de los almojarifazgos de Sevilla, cargo que disfrutó su esposo, Luis Méndez Guerrero ${ }^{65}$. Más arriba citamos el caso de Carolea Marbán, beneficiaria en 1697 de una magistratura de justicia en la audiencia de La Coruña. Otra hermana suya, también camarista de la reina, Teresa Marbán, recibió en 1704 una merced dotal de fiscal del Consejo de Guerra, la cual ocupó su esposo, Juan

62 FERNÁNDEZ DE BETHENCOURT, F.: Historia genealógica y heráldica de la Monarquía Española, Casa Real y Grandes de España, Madrid, 1897-1920, T. V, p. 303.

63 ÁLVAREZ-OSSORIO ALVARIÑO, A.: "De la plenitud territorial a una prolongada agonía: el Consejo de Italia durante el reinado de Felipe V", en Cheiron, Marteriali e strumenti di aggiornamento storiografico, 39- 40, 2003, p. 323.

64 ÁlVAREZ Y BAENA, J.: Hijos de Madrid, ilustres en santidad, dignidades, armas, ciencias $y$ artes, Madrid, 1789, p. 414.

65 AGS, Consejo y Juntas de Hacienda, Leg. 1410. 
Antonio Salcedo Morquecho ${ }^{66}$. Una tercera hermana, Juana, igualmente camarista de la reina, recibió una meced pecuniaria en 1699 por importe de medio millón de maravedíes al salir de palacio para casar con Francisco Ponce de León ${ }^{67}$. Por último, María Teresa Marbán, camarista de la reina, salió de palacio con una merced dotal de Secretario del Consejo de Cruzada, del cual se benefició Juan de Araujo, empleo del que sería depuesto en 1708, si bien la esposa no quedó sin la renta pues desde ese momento pasó a percibir la mitad del goce salarial de dicha secretaría ${ }^{68}$. La sobrina de las anteriores, Ursula Torres Marbán, casó en noviembre de 1694 con Manuel Aperregui a quien, en virtud de ese matrimonio, lo hizo Secretario de la Secretaría de la Junta de Reales Descargos, pues el monarca se lo había concedido como merced dotal "para que saliese casada de palacio" 69.

\section{Las mercedes dotales en el siglo XVIII}

En el siglo XVIII se mantuvo la dinámica heredada de la centuria precedente, al menos hasta 1751, fecha en que registramos la última merced dotal para servir un cargo. Al margen de las que se concedieron a cortesanos para ejercer en los oficios de palacio -cuyo estudio precisaría de una investigación monográfica-, fuera del mismo, en esa primera mitad del siglo, hemos podido documentar la existencia de un total de 75 mercedes dotales para ejercer diversos cargos, en su mayoría en las instituciones citadas más arriba: 30 plazas de contadores de la Contaduría Mayor de Cuentas, 19 magistraturas de justicia - buena parte de ellas en las Chancillerías de Granada y Valladolid, incluyendo además dos fiscalías importantes, una en la Casa de Contratación de Sevilla y otra en el Consejo de Hacienda-, 11 plazas de consejero en los Consejos de Hacienda e Indias y 7 cargos para desempeñar diversos empleos en el propio palacio del que manaban esas mercedes dotales. El resto se distribuyeron por empleos diversos, tales como una secretaría de la Junta de Reales Descargos, dos relatorías, una en la Junta del Tabaco y otra en la Casa de Contratación, una escribanía del registro del Consejo de Aragón e incluso una plaza de secretario de la Inquisición de Sevilla.

Tras el final de la operación venal de 1711, decreció el número de nuevas mercedes dotales para ejercer cargos, pero continuaron las concesiones en los mismos ámbitos institucionales en que lo venían haciendo desde el siglo XVII. De ese conjunto, dos merecen ser individualizadas por las especiales casuísticas que presentan. La primera, fue una merced dotal excepcional, concedida por un "mérito político", no por un servicio cortesano. En septiembre de 1736, Francisco Manuel Herrera,

66 AHN, Estado, Leg. 6403.

67 AGP, Reinados, Felipe V, Leg. 278.

68 AGS, Estado, Lib. 428.

69 AGS, Estado, Lib. 425. 
consejero de Guerra, fue agraciado con una merced dotal de fiscal de la Casa de Contratación por los méritos contraídos en su labor como comisario para la discusión del Tratado de Sevilla ${ }^{70}$. La agraciada fue su hija Gertrudis Herrera, quien hizo fiscal de la Casa de Contratación a José Alcedo, hasta entonces Catedrático de Cánones en la Universidad de Alcalá de Henares ${ }^{71}$.

La segunda merced dotal singular, a diferencia de la anterior, tuvo su origen en los servicios prestados en palacio, y se dio para servir en el mismo. Sus avatares, por extenso, han sido descritos de forma detallada por Elena Serrano ${ }^{72}$. Se trata de una merced dotal concedida en noviembre de 1736 a Ana Micaela Lacombe -por los servicios prestados como ayuda de cámara del rey por su padre, Juan Bautista Lacombe- de futura, ausencias y enfermedades de la veeduría de la Real Caballeriza de la reina. Ese mismo año, Ana Micaela casó con Manuel Pétriz y Manrique, quien en el mismo mes de noviembre de 1736 ya había sido nombrado ayuda de cámara del rey, de tal modo que acumuló dos empleos en palacio. En plena crisis de la hacienda real se decretó en 1739 la suspensión de la percepción de dos salarios por parte de un mismo servidor público, pero en palacio todo era posible. Allí permanecía aún como ayuda de cámara del rey, y al parecer con gran ascendencia sobre el monarca, Juan Bautista Lacombe, quien poesía, además, una futura de jefe de guardarropa del rey, que pasó a servir de forma efectiva en 1742 al morir el titular del oficio ${ }^{73}$. En 1739, un recién nacido, Francisco Pétriz Lacombe, hijo y nieto de los citados, recibió nombramiento de ayuda de cámara del rey con su correspondiente sueldo y gajes. Fue la fórmula ideada para que Manuel Pétriz sorteara el decreto de prohibición de percibir más de un sueldo, y para que asegurara la transmisión en la familia de su oficio de ayuda de cámara del rey. Se trata, sin duda, de un excelente ejemplo de la complicada madeja de los empleos de palacio, patrimonializados en manos de familias que lograron convertir los cargos en bienes patrimoniales, y que, cuando carecían de sucesión masculina, encontraban en las mercedes dotales un excelente mecanismo para perpetuar los empleos en el seno familiar. ${ }^{74}$ Era pues, un sistema cerrado, poco permeable a la incorporación de elementos externos a los grupos familiares que gozaban del favor regio.

70 AHN, Consejos, Lib. 736.

71 AGI, Indiferente General, Leg. 543, L. 3.

72 SERRANO GARCÍA, E.: "El acceso a los oficios de la caballeriza de la reina en tiempos de Felipe V...”, pp. 375-376.

73 AGP, Reinados, Felipe V, Leg. 272.

74 Otro caso evidente de patrimonialización se detalla en el estudio de Elena Serrano relativo a la concesión de un empleo de guardanés en 1643 para la persona que casare con Juana de Luna y Girón. Casada con Pedro de la Russa Rivera, logró en 1664 una nueva merced del rey al permitir la transmisión del mismo empleo a una de sus cuatro hijas para dotar su matrimonio. Tras recaer la merced en Catalina de la Russa Rivera, la plaza de guardanés fue ocupada por José Girón al casar con aquella. Como quiera que este último falleciera a edad temprana, Catalina conservó la propiedad de la plaza, sirviéndola de forma interina mediante sustitutos hasta colocar en 1715 a su yerno Juan Bautista de Iztueta como interino en esa 


\section{a) La década de los años cuarenta del siglo XVIII}

A partir del año 1739, coincidiendo con la apertura de una nueva operación venal, se reactivó la concesión de mercedes dotales. Hasta que a mediados de siglo se interrumpa por completo esta práctica, se iban a conceder, como mínimo, trece nuevas mercedes dotales para servir empleos de jueces, consejeros y contadores. Lo más significativo de esta última hornada no es el número sino la calidad de las gracias concedidas. Su distribución lo clarifica con rotundidad: tres en la Contaduría Mayor de Cuentas, dos puestos en las Reales Caballerizas, tres plazas de oidores y, lo más importante, un total de cinco plazas de consejeros, distribuidas entre el de Hacienda y el de Indias.

Un análisis minucioso de las mujeres agraciadas con mercedes para mejorar su dote permite corroborar la tesis que venimos manteniendo: que algunas se utilizaron para recompensar a criadas reales -y en menor proporción hombres- por servicios prestados en la proximidad de los monarcas, pero que también otras fueron a parar a personas sin vinculación con los empleos cortesanos. De las trece concedidas desde 1739, la mitad correspondieron a mujeres que habían tenido relación muy estrecha con la reina Isabel de Farnesio. El resto, al no proceder de un servicio palatino, y teniendo en cuenta que se concedieron en un período en que se vendían cargos, al menos entre 1739 y 1745 -etapa en que se conceden todas ellas menos una-podrían tener un origen más ligado a la venalidad que al "mérito", si bien en algún caso se pudo sustentar la obtención de semejante gracia en hipotéticos méritos políticos al servicio de la monarquía.

Las mercedes concedidas para servir en cada uno de los grupos de cargos referidos ponen de manifiesto esta dualidad. En la Contaduría Mayor de Cuentas, Margarita Milón Franqueza, por los méritos de su tío Juan Milón, obispo de Edesa, que había sido confesor de la reina Mariana de Neoburgo, consiguió una merced dotal de contador que desempeñaría Joaquín Elexpuru Marbán ${ }^{75}$. En sentido contrario, en 1740 Francisco García Valdés había actuado como contador en una operación de venta de empleos que dirigía como principal depositario el baztanés Miguel Arizcun. Dos años después del inicio de aquella empresa venal, García Valdés recibió como merced dotal una plaza de contador de resultas de la Contaduría Mayor de Cuentas para su sobrina María Rosa Martínez Valdés, de la cual se acabaría beneficiando Fernando Fernández Madrid al casar con ella en el año $1745^{76}$. Es evidente que García Valdés no ejercía

plaza. Tras la muerte de Catalina en 1723 la plaza fue otorgada en propiedad a su yerno, quien la disfrutó hasta su muerte en 1730. De este modo, durante varias generaciones, el empleo permaneció en manos de la misma familia. Cif. SERRANO GARCÍA, E.: "El acceso a los oficios...”, pp. 375-376.

75 AGS, Dirección General del Tesoro, Inv. 13, Leg. 2, Exp. 1.

76 AGS, Dirección General del Tesoro, Inv. 13, Leg. 1, Exp. 7. 
cargo alguno en palacio, pero por sus manos pasaba todo el dinero que la venta de cargos producía en aquellos años, y conocía con detalle los mecanismos a seguir para lograr que quedase perfectamente disimulada una merced para dotar a su sobrina. La tercera merced recayó en 1740 en Isabel Borrás, tras la muerte de su padre, Pedro Borrás, mariscal de campo, y por tanto sin relación con empleo cortesano alguno.

Las dos mercedes dotales para ejercer cargos en palacio, en concreto en las caballerizas, responden a ese mismo doble origen. En el año 1740 una criada de cámara de la reina, Isabel Moro, recibió una merced de veedor y contador de las Reales Caballerizas para quien casase con ella. Tras el matrimonio, el beneficiado sería Pedro de Alcázar Montoya, que por entonces servía como caballerizo de campo de la reina $^{77}$. En el polo opuesto, en ese mismo año de 1740, recibió una merced dotal de caballerizo de campo Carlos Ríos, quien por entonces tenía el grado de coronel y era gobernador de Tuy ${ }^{78}$. Su trayectoria profesional, siempre vinculada al ejército, en regimientos ordinarios - no los de las Guardias Reales-, no permite inferir que tuviese relación alguna con empleos cortesanos.

Algo similar sucedió con dos de las tres plazas dotales de oidores concedidas por Felipe V en 1743. Mariana Haubert Ochavart, nieta de un ayuda de cámara del rey, e hija de Antonio Ochavart, un capitán del regimiento de Guardias Walonas de Infantería, y de Hipólita Lacombe, perteneciente a una familia que había ocupado diversos empleos en la Corte, recibió una merced dotal de oidor de la Chancillería de Granada para quien casare con ella ${ }^{79}$. Un hidalgo granadino, José Faustino Pérez Hita, que había sido colegial del Colegio de Santa Cruz de Valladolid, se convirtió en oidor de Granada por su "mérito matrimonial". En teoría, Mariana había conseguido la merced "en atención a los particulares servicios de su padre", pero, en nuestra opinión, un grado de capitán de Guardias Walonas no era un rango tan relevante como para que su hija fuese dotada con una plaza de oidor ${ }^{80}$. Las Guardias Walonas tenían oficiales de mayor graduación, de mayor rango nobiliario y con más méritos en los campos de Marte como para haber sido recompensados con una gracia similar a la obtenida por Antonio Ochavart"1. Sin duda otros factores, otros "méritos", debieron intervenir en la concesión de esa merced dotal. Y algo similar debió suceder con María Teresa Hurtado de Mendoza, hija del marqués de Gauna, teniente general, que se vio favorecida en 1743 con una merced dotal de oidor de la Chancillería de Va-

77 AGS, Dirección General del Tesoro, Inv. 2, Leg. 32.

78 AGS, Gracia y Justicia, Lib. 316.

79 AHN, Consejos, Lib. 736.

80 Cfr. GÓMEZ GONZÁLEZ, I.: Op. cit., p. 128.

81 GLESENER, T.: La Garde du roi. Pouvoirs, élites et nations dans la monarchie hispanique (1700-1823), Tesis doctoral inédita. 
lladolid, de la cual se beneficiaría José Manuel de Villena al casar con ella en el mes de agosto del año siguiente ${ }^{82}$. Tampoco se observa en este caso un importante puesto cortesano que hubiera alentado la concesión de tal merced por parte del monarca. Por último, la tercera plaza, sí que tuvo un origen claramente en el servicio cortesano, pues se concedió en ese mismo año de 1743 a Francisca Castañeda, camarista de la reina, quien al casar con Francisco Granados lo convirtió en oidor supernumerario de la Chancillería de Valladolid ${ }^{83}$.

Pero, sin duda, de cuantas mercedes dotales se concedieron en este período las más importantes fueron las plazas de consejero de los Consejos de Hacienda e Indias. En este caso, la influencia de las mujeres más próximas a la reina Isabel de Farnesio se dejó notar sobremanera como factor determinante, aunque resulta de todo punto imposible precisar si esa influencia fue el único elemento que hizo inclinar el favor real en beneficio de cada una de ellas.

Así, poco antes de 1739, o probablemente en ese mismo año, una irlandesa, Isabel O'Brien O'Connor, camarera de la reina, fue agraciada con una merced dotal de consejero de Hacienda para quien con ella casare ${ }^{84}$. Con semejante dote, la camarera no iba a enlazar con cualquiera, sino nada menos que con Félix Salabert Aguerri, marqués de Valdeolmos, importante financiero de Felipe V, que había casado en primeras nupcias con la hija del marqués de Santiago, también financiero y prestamista del monarca, a la sazón una de las grandes fortunas de la época ${ }^{85}$. No elegía mal el financiero: en primeras nupcias, dinero, en segundas, poder, esta vez como consejero de Hacienda, un empleo que le serviría de antesala para mayores metas, pues en agosto de 1746 se introdujo de pleno en la Corte como Mayordomo de Semana de la reina y en mayo de 1749 como Mayordomo de Semana de Fernando VI. Por el momento resulta imposible discernir qué fue antes, si el concierto matrimonial del marqués de Valdeolmos con quien ya había sido favorecida con semejante merced, o un acuerdo del poderoso financiero para hacerse por esa vía con un sillón de consejero de Hacienda. Sólo es posible constatar, por un lado, el servicio cortesano de una mujer cerca de la persona de la reina Isabel de Farnesio y, por otro, caudales sobrados como para vencer voluntades.

82 AHN, Consejos, Lib. 736.

83 CASTELLANO, J. L.: "La carrera burocrática en la España del siglo XVIII", en CASTELLANO, J. L. (Ed.): Sociedad, Administración y Poder en la España del Antiguo Régimen, Granada, 1996, p. 32.

84 AHN, Consejos, Lib. 736. Sobre la estrategia matrimonial del importante grupo de camaristas irlandesas que sirvieron en la Corte en tiempos de Felipe V véase ANDÚJAR CASTILLO, F.: "Familias irlandesas en el ejército y en la Corte borbónica", en GARCÍA HERNÁN, E. - RECIO MORALES, O. (Coords.): Extranjeros en el ejército. Militares irlandeses en la sociedad española, 1580-1818. Madrid, 2007, pp. 271-295.

85 Vid. HERNÁNDEZ, M.: A la sombra de la Corona. Poder local y oligarquía urbana (Madrid, 1606-1808), Madrid, 1995, p. 176. 
En el mismo Consejo de Hacienda por esas mismas fechas recibió una merced dotal de consejero María Francisca Téllez de Canencia. El mérito parecía estar en su madre, Teresa Canencia, quien desde 1724 ocupaba el cargo de "dueña del retrete de la reina"86. En 1745 casó con Miguel Domingo Cuadros, ayuda de cámara del rey, hijo de Vicente Cuadros, quien había desempeñado con anterioridad ese mismo puesto. En ese matrimonio, que suponía segundas nupcias para Miguel Domingo, parecían converger los intereses de dos familias asentadas en palacio, para acumular, además de poder, dos salarios. Es probable que las influencias de quienes servían al rey y a la reina confluyeran en una merced que acabó favoreciendo notablemente a Miguel Domingo Cuadros, pues en 1750 se jubiló como ayuda de cámara del rey pero siguió percibiendo el salario de consejero de Hacienda hasta su muerte en noviembre de 1769.

Los privilegios de servir junto a los soberanos se extendieron aún más durante estos años. En 1751 Diego Joaquín Ortíz de Guinea, con tan sólo 25 años de edad, obtuvo un despacho real por el que se le nombraba consejero supernumerario del Consejo de Hacienda ${ }^{87}$. El mérito que presentaba para tan alta distinción consistía en haber casado con María Manuela de Terán, nieta de Diego de Terán, marqués de Terán, ayuda de cámara del rey y aposentador mayor de palacio, a quien años antes se le había hecho tal merced para dotar el casamiento de su nieta. Por otra parte, su abuela tenía también buenas relaciones en la Corte, pues su padre, Juan Molinet Girón, había sido tesorero de la reina Mariana de Austria. En principio, se trataba de una gracia que encajaba dentro de la lógica de los parabienes que reportaba el servicio junto a las reales personas. Por su parte, el marqués de Terán, además de los cargos palatinos, poseía una gran fortuna, merced a la cual había conseguido, entre otros bienes, el puesto de secretario del Consejo de Inquisición en 1712, cargo que heredaría su hijo Francisco Antonio, padre de María Manuela, la favorecida con la merced dotal de consejero de Hacienda $^{88}$. Por ende, de nuevo estamos ante un caso en el que el triangulo formado por el ejercicio de cargos cortesanos, una considerable fortuna familiar, y una merced dotal otorgada por el monarca, venían a converger en una misma mujer.

Si en los casos anteriores se constata el servicio cortesano como elemento fundamental para la obtención de la merced dotal, en el del marqués de Montealto, que fue "agraciado" con una merced de consejero de Indias en septiembre de 1741 no se encuentra relación alguna con la Corte. Urbano Ahumada Guerrero, que había sido corregidor de Cáceres y Valladolid, había obtenido ya en 1728 un "excepcio-

86 AHN, Consejos, Lib. 737.

87 AHN, Consejos, Lib. 737.

88 El patrimonio de Francisco Antonio en 1773 era de cerca de 1.800.000 reales. Cfr. HERNÁNDEZ, M.: Op. cit., pp. 110-111. 
nal" nombramiento como consejero supernumerario del Consejo de Hacienda por el que percibiría, además, la mitad del sueldo hasta ocupar una plaza del número ${ }^{89}$. La mayor parte de esas plazas supernumerarias en los años precedentes correspondían a sendas operaciones de compra de las mismas. En junio de 1731 promocionó hasta corregidor de Madrid y al año siguiente se hizo con el título nobiliario de marqués de Montealto. Tras recibir la merced dotal de consejero de Indias en 1741, su hija casará con el gallego Antonio Jacinto Romay, doctor en cánones por la Universidad de Santiago, título que le serviría para desempeñar el puesto de consejero togado del Consejo de Indias aportado por su esposa ${ }^{90}$. Como se comprueba, sin relación alguna con empleos de palacio, se trataría de una merced dotal producto de su cargo como corregidor de Madrid y probablemente de algún "mérito adicional".

\section{b) La familia Piscatori y las mercedes dotales}

Deliberadamente situamos al final el ejemplo que podría considerarse como paradigma de las mercedes dotales logradas por la confianza y el favor regio en la proximidad de los monarcas, en este caso, cerca de la reina Isabel de Farnesio. Los rendimientos pecuniarios en forma de cargos obtenidos por la familia Piscatori constituyen el ejemplo más preclaro de la liberalidad regia para con sus servidoras más fieles. Su interés deviene, no tanto de las mercedes en sí, como de los avatares que experimentaron dos plazas dotales de consejeros de Indias concedidas a Isabel Piscatori -hija de Laura Piscatori-y a su prima Mariana. A ellas se suman otras gracias obtenidas por Lucio Piscatori, hermano de Isabel, y por María Teresa, hermana de Mariana. La mayor parte de estas mercedes fueron estudiadas en su día por el profesor Juan Luis Castellano y son ahora objeto de ampliación en las páginas que siguen ${ }^{91}$.

Laura Piscatori, la nodriza de Isabel de Farnesio, y luego su amiga de confianza, logró tener gran ascendencia sobre la reina. Sus críticos resaltaron el gran predicamento que tuvo en la Corte, acusándola de aprovechar su influencia en beneficio propio o de sus parientes y amigos ${ }^{92}$. Razones no faltaban a esos críticos, pues entre otras cosas, como mínimo, colocó a su hija y a su sobrina en palacio, y para ambas consiguió prebendas de enorme valor.

Gracias a su influencia, Isabel Piscatori, su hija, debió recibir a los pocos años de su llegada a España una merced de consejero de Indias para su futuro esposo. Y en

89 AGS, Dirección General del Tesoro, Inv. 13, Leg. 3, Exp. 9.

90 AHN, Consejos, Lib. 736.

91 Varios de estos enlaces se encuentran documentados en CASTELLANO, J. L.: "La carrera burocrática...”, pp. 34-35.

92 PÉREZ SAMPER, Ma A.: Isabel de Farnesio, Barcelona, 2003, p. 107. 
efecto, en abril de 1723 concertó su casamiento con Pedro Casado, hijo del marqués de Monteleón, Isidro Casado ${ }^{93}$, diplomático de origen italiano, hábil experto en la compra de cargos, pues en 1711 había conseguido hacerse con una plaza supernumeraria de consejero de Indias gracias a un decreto del rey, es decir, sin intervención alguna de la Cámara. Por entonces, el marqués de Monteleón, protegido por Laura Piscatori, se ocupaba del seguimiento de las negociaciones del Congreso de Cambrais ${ }^{94}$. Que sepamos, hacia 1723 se habían dejado de vender ya los importantes puestos de los Consejos $^{95}$, pero existían otras fórmulas para sentarse en sus sillones siguiendo caminos menos tortuosos y largos que aquellos por los que discurrían los cursus honorum "reglados" u ordinarios. Se podía atajar ese camino casando con quien disfrutara de una merced dotal, y Pedro Casado concertó su matrimonio con una mujer que le aseguraba una plaza de consejero de Indias -en el mismo Consejo que su padre-, que obtendría desde el mismo día de la firma de las capitulaciones matrimoniales. El 13 de abril de 1723 Pedro Casado recibió su título de consejero del Consejo de Indias en virtud de tales acuerdos ${ }^{96}$. Sin embargo, por razones que ignoramos, aquella boda se frustró y dos años más tarde Pedro Casado fue cesado en su cargo.

La camarera de la reina no perdió la merced que le concediera Felipe V -puesto que de una merced vitalicia se trataba- y en diciembre de 1725 fue nombrado consejero del Consejo de Indias otro italiano sin experiencia alguna en los manejos de la administración indiana, Luis Yopulo Espadafora, duque de San Blas, un exempto de la compañía italiana de Guardias de Corps. Lo más probable es que Luis Yopulo se limitara a percibir el salario de consejero de Indias, pues siguió la carrera militar, en la cual sería promovido a brigadier el 1 de julio de 1732, unos días antes de que falleciera en Orán ${ }^{97}$.

Tras su muerte, Isabel Piscatori volvió a casar de nuevo, esta vez con su cuñado, Diego Yopulo Espadafora, también de profesión militar, quien por entonces ostentaba ya el grado de brigadier de caballería. La merced dotal se hizo efectiva de nuevo, y Diego Yopulo obtuvo su título de consejero de capa y espada del Consejo de Indias con fecha de 21 de enero de $1735^{98}$. Al igual que su hermano, siguió la ca-

93 La trayectoria de la familia de los Casado puede seguirse en la obra de ÁLVAREZ-OSSORIO ALVARIÑO, A.: La república de las parentelas. El Estado de Milán en la monarquía de Carlos II, Mantua, 2002. Una síntesis sobre Isidoro Casado se encuentra en OZANAM, D.: Les diplomates espagnols $d u$ XVIIIe siècle, Madrid, 1998, pp. 117-118.

94 PÉREZ SAMPER, Ma A.: Op. cit., p. 187.

95 Tan sólo parecen registrarse dos o tres operaciones de este tipo en los últimos años del reinado de Felipe V.

96 AHN, Estado, Leg. 6380.

97 Gaceta de Madrid, 1 de julio de 1732.

98 AHN, Estado, Leg. 6380. 
rrera militar, en la cual alcanzó el grado de teniente general de los reales ejércitos, y desde enero de 1760 desempeñó el puesto de Comandante General de Guipúzcoa ${ }^{99}$. No parece que ejerciera el cargo de consejero de forma efectiva pero sí debió percibir el correspondiente salario que acumularía al de su grado militar.

La vinculación de la familia Piscatori con el Consejo de Indias no acabó con los matrimonios de Isabel. Su prima, Mariana Piscatori, criada de cámara de la reina Isabel de Farnesio, también fue agraciada con otra merced dotal de consejero de Indias para que la disfrutase quien casara con ella. Lo sucedido en este caso presenta numerosas similitudes con la trayectoria de su prima. En octubre de 1743 Mariana concertó su casamiento con el conde de Portillo y, en virtud de tal acuerdo, el día 1 de octubre de aquel año, José Joaquín Sarmiento Sotomayor, a la sazón corregidor de Cumaná -puesto que había comprado en enero de 1740 por 68.000 reales ${ }^{100}$ - recibió su correspondiente título de consejero de Indias. Pero tan desorbitado "ascenso" fue suspendido poco después porque el acuerdo de casamiento con Maríana Piscatori se rompió, al igual que había sucedido entre su prima y Pedro Casado. Sin embargo, tardó muy poco tiempo en cambiar de pretendiente. Unos meses después de su primera tentativa contrajo matrimonio con Felipe Arco Riva Aguero, el cual, en virtud de tal alianza, obtuvo su título de consejero de Indias con fecha de 11 de julio de $1744^{101}$.

La red de influencia de la familia Piscatori se extendió hasta el Consejo de Hacienda, en donde Lucio, hermano de Isabel Piscatori, obtuvo plaza de consejero en mayo de 1741. Fallecido en diciembre de ese mismo año, el cargo lo "heredó" su hijo Francisco, marqués de San Andrés ${ }^{102}$, que recibió nombramiento de consejero de Hacienda con el fin de que su madre pudiera percibir una pensión para su sustento ${ }^{103}$. Con una estrategia matrimonial muy calculada, y sustentada en las jugosas dotes que aportaban sus enlaces, la familia Piscatori tuvo en María Teresa, hermana de Mariana, el último elemento que venía a cerrar un completo círculo marcado por una gran influencia sobre Isabel de Farnesio, claramente reflejado en la "calidad" de las merce-

99 AGS, Dirección General del Tesoro, Inv. 2, Leg. 44.

100 AGI, Indiferente General, Leg. 525, L. 1.

101 AHN, Estado, Leg. 6380. Felipe Arco, natural de Villaverde de Trucios, en Santander, era sin duda pariente -probablemente sobrino- de Felipe Arco Agüero, un personaje que en febrero de 1696 compró por la considerable suma de 35.000 ducados, pagados al contado, la Tesorería General de los Efectos de la Cámara de Castilla, en la cual se ingresaban los derechos de las denominadas "gracias al sacar" y se percibía el producto de la venta de hidalguías y otros honores que concedía el rey. En ese puesto permaneció hasta su muerte en agosto de 1785, tras haber sido promovido a camarista de Indias en septiembre de 1770. Cfr. en BURKHOLDER, M. A.: Biographical Dictionary of Councilors of the Indes, 1717-1808, New York, 1986, p. 11.

102 Título nobiliario concedido en agosto de 1733 a Fulvio Piscatori, marido de Laura, azafata de la reina Isabel de Farnesio, y principal impulsora de todos los favores y mercedes que recibió la familia.

103 AGS, Dirección General del Tesoro, Inv. 13, Leg. 1, Exp. 7. 
des dispensadas. María Teresa Piscatori, criada de la reina, casó en 1744 con Antonio María Díaz Lavandero, hijo del marqués de Torrenueva, un importante asentista que había llegado a ser Tesorero General y Secretario del Despacho de Hacienda entre noviembre de 1736 y marzo de 1739. María Teresa aportó al matrimonio una plaza de mayordomo de semana del rey "con calidad de dotal, con el sueldo y emolumentos que gozan los quatro del número"104. Por su parte, Antonio María Díaz Lavandero, debió aportar también la sustanciosa pensión que, "por los méritos de su padre", había recibido del rey en diciembre de 1736 - cuando contaba con tan sólo 11 años de edadpor importe de 1.500 doblones anuales situados sobre las labores de la Casa de Moneda de México o sobre los oficios vendibles y renunciables de Nueva España ${ }^{105}$.

En suma, las rentas y honores proporcionados a Laura Piscatori no fueron nada desdeñables para una familia que se aseguró el futuro de varias de sus mujeres al obtener puestos que situaban a sus consortes en las más altas magistraturas de la monarquía ${ }^{106}$. Prestigio, poder, y un elevado salario, constituían tres elementos demasiado jugosos como para que los casamientos de las mujeres que habían servido en palacio se hicieran con hombres que, por su parte, aportaran al matrimonio riqueza y dignidades que ampliaran y reforzaran el lustre de la familia. Nótese que de un total de siete casamientos que realizaron las Piscatori, seis de ellos se formalizaron con miembros o hijos de la nobleza titulada -italiana en el caso de Isabel-que aportaron al matrimonio sendos Títulos de Castilla. En el vasto mercado matrimonial cortesano, las mujeres aportaron el cargo a los nobles titulados y, a cambio, éstos, amén del salario y del honor correspondiente al empleo, lograron aproximarse aún más al centro del poder y del favor regio. Como ha escrito Enrique Soria, las mercedes dotales fueron un buen "cebo" para atraer a ambiciosos pretendientes a ese mercado ${ }^{107}$ que siempre se articuló en torno a relaciones de mutua reciprocidad entre los cónyuges. Unas podían aportar capital relacional, otros capital económico, lo mismo que otros aportaban prestigio y honor a cambio de un empleo que significara poder y proximidad al monarca.

104 Cfr. en CASTELLANO, J. L.: "La carrera burocrática...”, p. 35.

105 AGI, Indiferente General, Leg. 543, L. 3.

106 La red familiar de los Piscatori se completa con la que sería también criada de la reina, María Teresa Piscatori, hija de Laura, que casó en 1721 con el parmesano Juan Francisco Cogorani, mayordomo de semana de la Real Casa, el cual años más tarde seguiría la carrera diplomática. Cfr. OZANAM, D. : Op. cit, pp. 232-233.

107 SORIA MESA, E.: La nobleza en la España Moderna. Cambio y continuidad, Madrid, 2007, p. 184. 


\section{Controles y críticas}

Según establecían las normas, ordenanzas y plantas de las instituciones en las que se concedían las mercedes dotales, los empleos no se podían proveer por casamiento, pero la liberalidad del rey era tan infinita como que podía contravenir siempre lo que él mismo había regulado. Para sortear los posibles escollos que pudieran suscitarse y en aras al buen funcionamiento de esas instituciones, cada vez que se concedía una merced dotal, se solía poner como condición que el sujeto que casare con la portadora de la merced fuese "idóneo" para ejercer las plazas que conseguían en virtud de su matrimonio ${ }^{108}$. Las reglas del juego eran siempre las mismas. Reiteradas disposiciones prohibían conceder plazas dotales pero las relaciones de patronazgo cortesanas acababan imponiéndose para dejar caer en saco roto esas mismas prohibiciones. Siempre prevaleció en los nombramientos la arbitrariedad, explícita tanto en las mercedes dotales como en la venalidad de los empleos y, en consecuencia, su influencia decisiva sobre aquellas parcelas de la administración de la monarquía en las que ambas prácticas tuvieron una mayor incidencia.

Las ordenanzas del Consejo de Hacienda de $1602^{109}$ establecían que las plazas de contadores de la Contaduría Mayor de Cuentas no se pudiesen dar en dote, pero se siguieron dispensando, como mínimo, hasta 1746, a pesar de la nueva prohibición impuesta por la nueva planta que se dio a dicha Contaduría en 1715. Una prohibición, del año 1623, era más extensiva aún, pues impedía que se diese en dote "ninguna plaza, ni oficio de justicia, ni potestad pública, ni alguno de nuestra Real Casa" ${ }^{110}$. Pero, eran tan numerosos los favores y tan amplias las clientelas que con ellos se configuraban por este particular camino de acceso a los cargos, que el sistema no se podía eliminar, porque en su desarrollo radicaba uno de los principales pilares de la formación de redes de poder cortesanas. No sólo no se limitaron las mercedes dotales sino que en el año de 1636 se creó una "Junta de Casamientos" encargada de gestionar todas las plazas que se concedían a las servidoras de las reinas en calidad de mercedes dotales ${ }^{111}$. Incluso, como ha mostrado Eduardo Montagut, los servicios de los criados inferiores de las Casas Reales y de las nodrizas fueron recompensados de forma sistemática con mercedes dotales para servir varas de alguaciles de Casa y Corte ${ }^{112}$.

108 Inés Gómez González ha mostrado que la "idoneidad" fue una quimera y que pese a algunos informes negativos de la Cámara de Castilla, muchos sujetos que lograron mercedes dotales acabaron desempeñándolas de forma efectiva. Cfr. GÓMEZ GONZÁLEZ, I.: Op. cit., pp. 128-130.

109 AGS, Consejo y Juntas de Hacienda, Leg. 555.

110 Novísima Recopilación, Libro XX, Tit. III, Ley VI.

111 SÁNCHEZ GONZÁLEZ, M. D.: Las juntas ordinarias, tribunales permanentes en la Corte de los Austrias, Madrid, 1995, p. 45.

112 MONTAGUT, E.: Op. cit., p. 86. 
El sistema de concesión de mercedes dotales tuvo escasos controles sobre la calidad de los individuos que casaban con sus portadoras, fundamentalmente por el propio hecho de que la merced se otorgaba con anterioridad a la comprobación de las calidades del beneficiado por el matrimonio. Así, para quien en virtud de una merced dotal se fuese a convertir en juez, era requisito imprescindible haber cursado leyes. Ese filtro era claro, pero no estaba tan definido cuando una merced dotal comportaba, por ejemplo, el ejercicio de una plaza de consejero de Indias. No era preciso estar versado en los asuntos del gobierno americano para sentarse en el consejo supremo de gobierno de aquel territorio. Lo mismo sucedía cuando la merced dotal tenía como destino el Consejo de Hacienda.

Inés Gómez ha señalado varios ejemplos de cómo en la Chancillería de Granada, en el siglo XVII, sirvieron algunos magistrados nombrados gracias a sus casamientos que, según el parecer de la propia Cámara de Castilla, no reunían los requisitos mínimos para ejercer como jueces. En ese mismo estudio, ha dado prueba del rechazo que suscitó en la Cámara de Castilla este tipo de mercedes, cual sucedió en mayo de 1668 a propósito de una plaza dotal concedida a María de Guerra y Vargas por "los inconvenientes que se siguen que las plazas se den por vía de casamiento, pues cada día se reconocen mayores por los muchos sujetos que han entrado por esta puerta de algunos años a esta parte [...]"113. La Cámara de Castilla reiteró en numerosas ocasiones a lo largo del siglo XVII su opinión contraria a que las plazas de justicia se diesen en merced dotal porque por este procedimiento "se dejaban de emplear en la administración de justicia los sujetos más dignos"114. Pero, como siempre, semejantes lamentos caían, una y otra vez, en el más absoluto de los olvidos.

En cuanto a los empleos de contadores de la Contaduría Mayor de Cuentas concedidos por merced dotal, la supervisión de los que iban a ejercer esos cargos en virtud de su matrimonio correspondía al Consejo de Hacienda ${ }^{115}$. En reiteradas ocasiones este Consejo elevó quejas al rey acerca de los problemas que ocasionaba este sistema de provisión de cargos para una labor burocrática que precisaba de unos conocimientos mínimos que tan sólo podían tenerse con la experiencia y con la "cría" en los empleos inferiores. En agosto de 1648, con motivo de un nombramiento de contador de resultas, para quien casare con la sobrina de un tal Blas Rodríguez, el Consejo de Hacienda elevó un memorial a Felipe IV en el que se quejaba de que se

113 GÓMEZ GONZÁLEZ, I.: Op. cit., p. 129.

114 Cfr. en MONTAGUT, E.: Op. cit. p. 86.

115 Por ejemplo, en marzo de 1707 se le concedió a Antonio de la Vega, aposentador de la Casa de la Reina, una merced dotal de contador de resultas de la Contaduría Mayor para quien casare con su hija, con la condición de que el esposo fuese "de la aprobación del Consejo de Hacienda". AGS, Estado, Lib. 421, fol. 333 . 
concedieran cargos de tanta importancia como los de contadores de resultas a personas sin experiencia "estando la Contaduría cargada de personas de esta calidad, y tan falta de sujetos que tengan noticias y experiencias que es menester buscarlos y honorarlos para que se inclinen en este ejercicio, porque viendo que estas plazas se extravían, y que no les queda esperanza con los muchos que han entrado por estos medios, no quieren continuar la ocupación, y se halla en estado que no hay seis contadores de quienes se pueda echar mano en una cuenta de importancia"116.

En términos muy similares volvió a manifestarse el Consejo de Hacienda cuando elevó una consulta al rey en enero de 1680 con motivo de la concesión de una plaza de contador de resultas para la persona que casare con Agustina Gómez Salinas, hija de don Pedro Gómez de Salinas. El Consejo, recordó al rey que esas mercedes contravenían tanto las ordenanzas como las cédulas últimas que habían reformado -léase suprimido-algunas de esas plazas, y que su ejercicio precisaba de personas de la "mayor inteligencia, experiencia y noticia" que se hubiesen criado en empleos inferiores, quienes por entonces se encontraban con "grande desconsuelo" a causa de haberse provisto durante los últimos años los oficios en personas de fuera de la profesión en un número superior al de la planta de la propia Contaduría Mayor de Cuentas. Concluía el Consejo de Hacienda que, a pesar de que la plaza concedida a Agustina debía ser con la condición de que la persona que casare con ella fuese a satisfacción del mismo Consejo, "será posible que no sea a propósito ni de las partes necesarias para una cosa tan importante, por la dificultad del examen, y el que se hallare con las partes necesarias no entrará en esta plaza por casamiento, y con el favor que alcanzó esta merced, pretenderá la de aprobación [...]"117. En suma, el Consejo de Hacienda rechazó esa merced dotal pero la resolución de Carlos II no dejó lugar a duda alguna sobre la competencia en la decisión: "Ejecútese lo resuelto y quedo enterado de lo que se me representa"118.

El mismo Consejo de Hacienda había recordado al rey, en otra consulta de noviembre de 1680, los perjuicios que se seguían de la concesión de mercedes dotales para servir contadurías. En esta ocasión se remitía a lo consultado por el Consejo en 1656, cuando el rey dio una merced dotal de "contador de la razón general de los almojarifazgos de Sevilla", que incluía el preciado "almojarifazgo mayor", empleo que era considerado por el propio Consejo como "la llave principal del buen gobierno de

116 Cfr. DOMÍNGUEZ ORTIZ, A.: Política fiscal y cambio social..., p. 159.

117 AGS, Consejo y Juntas de Hacienda, Leg. 1410. Consulta del Consejo de Hacienda de 25 de enero de 1680 .

118 Años después, en 1698, se repitió el mismo escenario en otra consulta del Consejo de Hacienda en la que se rechazaba la merced dotal de contador de resultas concedida a una hija de Manuel Sicardo. Cfr. SÁNCHEZ BELÉN, J. A.: La política fiscal en Castilla ..., p. 23. 
las rentas de los almojarifazgos". En esa ocasión el Consejo rechazó que la merced dotal recayese en Luis Méndez Guerrero por su matrimonio con Leonor Marbán y Mallea, por carecer de las "noticias y experiencias que se precisaban" y por exponerse la hacienda a "una pérdida considerable en la alaxa de más valor que $\mathrm{Su} \mathrm{Ma}$ jestad tenía en el Real Patrimonio"119. En 1656, cual había ocurrido con la merced de Gómez Salinas en 1680, de nada sirvió el rechazo del Consejo de Hacienda al nombramiento de Luis Méndez, porque ya se había efectuado la boda y no cabía otra alternativa que acatar la resolución real que contenía el nombramiento.

Añadamos a todo lo expuesto el problema de los comisionados para el "control de la calidad" de los beneficiados por las mercedes dotales. La competencia para juzgar a oidores y consejeros debió residir, al menos en teoría, en la Cámara de Castilla, pero bastaba con acreditar haber cursado estudios de Derecho. Como hemos visto, el control de los contadores de hacienda era, igualmente, competencia de un Consejo de Hacienda que poco podía hacer una vez que se había consumado el matrimonio por el que se hacía a un individuo contador. De las mercedes dotales concedidas en el siglo XVIII, tan sólo conocemos un caso de anulación, registrado el año 1724, por no ser adecuado para el puesto de contador de la Contaduría General de Valores Lorenzo Correa, quien lo había obtenido por su matrimonio con Benita San Martín. No obstante, en compensación, la beneficiaria pasó a percibir una merced pecuniaria por importe de 200 ducados anuales, prueba evidente del valor sustitutivo que las mercedes dotales de "honores y cargos" tenían en relación con las remuneratorias que recaían sobre las arcas reales ${ }^{120}$.

La ineficacia del proceso de control de concesión de estas mercedes radicó en el origen mismo del sistema. En el caso de las plazas de justicia y de las magistraturas de los Consejos, el rey, mediante un decreto ejecutivo, ordenaba a la Cámara que se procediese a la expedición del correspondiente nombramiento. En teoría, la Cámara, al mismo tiempo que procedía a ejecutar el dictado regio, debía revisar las calidades del pretendiente a casar con la mujer agraciada con la merced dotal. La reversión del procedimiento comportaba la dificultad inherente a que la sanción regia se había producido con antelación a la comprobación de las calidades de los que iban a contraer ese matrimonio. Difícilmente se podía revocar un decreto real y, por tanto, la Cámara todo lo más que podía hacer era manifestar su parecer sobre la idoneidad del dotado con la merced. Tan complejo era que un decreto real sustentado en el dinero se anulase como que se llegara a ese mismo punto en caso de un matrimonio con persona

119 AGS, Consejo y Juntas de Hacienda, Leg. 1410. Consulta del Consejo de Hacienda de 26 de noviembre de 1680 .

120 AGS, Dirección General del Tesoro, Inv. 13, Leg. 1, Exp. 3; AHN, Consejos, Leg. 7933. 
poco adecuada al puesto a desempeñar. En el fondo estaba el mismo problema. La potestad regia, la liberalidad total, aún existiendo mecanismos de control como el de la Cámara de Castilla, chocaba frontalmente con los procedimientos extraordinarios que, en virtud del poder del soberano, quebraban la vía consultiva. Idénticas circunstancias se producían cuando se vendían cargos, pues el rey aceptaba el dinero y efectuaba el nombramiento, igualmente mediante un decreto ejecutivo, sin reconocer más mérito que el dinero. Las miles de patentes en blanco firmadas por el rey para nombrar anónimos oficiales del ejército que se registran en el ejército en el siglo XVIII ejemplifican con precisión hasta qué punto el poder del soberano fue tan absoluto como limitado por la constantes demandas de recursos financieros ${ }^{121}$.

Con una merced "para tomar estado" el rey premiaba, fidelizaba a servidores, reforzaba los vínculos con sus súbditos, pagaba un salario, que tendría que abonar en cualquier caso, pero no incrementaba el siempre lesivo capítulo del gasto en forma de pensiones y mercedes pecuniarias. En el otro lado de la balanza quedaba un sistema político-administrativo articulado en torno a las dos varas de medir que el rey utilizaba para seleccionar a sus agentes: una la que seguía la vía ordinaria, y la otra que traslucía sin ambages su poder absoluto. Era pues un sistema propio del modelo doméstico de relación política en el que, como señaló Antonio Manuel Hespanha, se premiaba la "fidelidad y la tradición de servicio por encima del mérito o de la adecuación a la función"122.

Poco importaba que el entramado administrativo de la monarquía se viera seriamente dañado - cual sucedía, en paralelo, con la venalidad-por un sistema de selección de los agentes de gobierno en el que por encima de la capacidad y del mérito primaba la arbitrariedad, el ejercicio del patronazgo regio en su máxima expresión y, a menudo, el predominio de las relaciones clientelares, en este caso de las clientelas cortesanas como mecanismo regulador de la "eficacia" de la maquinaria políticoadministrativa. Y es que, en palacio, más que en ningún otro sitio, allí donde se tejía la "hebra de los empleos", como la definiera el duque de Montalto en 1658 "123, se hilaba para labrar, por la vía matrimonial, "prendas" que mejoraran el patrimonio de las servidoras y servidores regios.

121 Vid. ANDÚJAR CASTILLO, F.: El sonido del dinero. Monarquía, ejército y venalidad en la España del siglo XVIII, Madrid, 2004.

122 HESPANHA, A. M.: La gracia del derecho. Economía de la cultura en la Edad Moderna, Madrid, 1993, pp. 185-187.

123 BOUZA, F.: "Servir de lejos. Imágenes y espacios del Cursus Honorum cortesano en la España de los Austrias", en Europa: proyecciones y perspectivas históricas, Salamanca, 1997, p. 84. 